\title{
Comparative photosynthetic attributes of emmer and modern wheats in response to water and nitrogen supply
}

\author{
M. VAGHAR and P. EHSANZADEH ${ }^{+}$ \\ Department of Agronomy and Plant Breeding, College of Agriculture, Isfahan University of Technology, Isfahan, \\ 84156-83111, Iran
}

\begin{abstract}
A field study was conducted with the aim to elucidate photosynthetic responses of five emmer hulled wheat (Triticum turgidum ssp. dicoccum) accessions to 30 (N-limited) and $100 \mathrm{~kg}(\mathrm{~N}) \mathrm{ha}^{-1}$ (N-sufficient) conditions at control and drought stress (irrigation after 30-40\% and 60-70\% depletion of available soil water, respectively). Chlorophyll (Chl) $a$ and Chl $b$ concentrations of the emmer wheats remained unchanged but net photosynthetic rate and dry mass increased and decreased, respectively, when received a sufficient amount of N. Smaller drought-induced decreases in Chl concentration, membrane stability index, and dry mass were concomitant to a greater decrease in intercellular $\mathrm{CO}_{2}$ concentration of emmer compared to the durum (Triticum turgidum) and bread wheats (Triticum aestivum). The lack of negative effect of insufficient $\mathrm{N}$ on $\mathrm{Chl}$ concentration and dry mass of emmer wheat suggests that this type of wheat possesses an obvious potential for organic farming.
\end{abstract}

Additional key words: chlorophyll; fertilizer; hulled wheat; irrigation; water-use efficiency.

\section{Introduction}

Inadequate $\mathrm{N}$ and water are known as two major limiting factors in plant growth and agricultural production (Lea and Azevedo 2006). Water scarcity is an ever-increasing problem in agriculture and achieving greater water-use efficiency (WUE) is a priority, to the extent that the policy of 'more crop per drop' has been adopted by the United Nations (Flexas et al. 2010). Both water and $\mathrm{N}$ availabilities may exhibit seasonal and ontogeny changes (Pan et al. 2011). Severe water stress depresses a number of photosynthetic components and/or functions, including pigment content, net photosynthetic rate $\left(P_{\mathrm{N}}\right)$, stomatal conductance $\left(g_{\mathrm{s}}\right)$, and maximal quantum efficiency of PSII $\left(F_{v} / F_{m}\right)$ (Yousefzadeh Najafabadi and Ehsanzadeh 2017) and may disturb nitrate metabolism. In fact, a set of enzymes involved in $\mathrm{N}$ metabolism, including nitrate reductase, glutamine synthetase, glutamate dehydrogenase, and endopeptidase are downregulated due to water deprivation. A positive correlation between leaf $\mathrm{N}$ content and light-saturated rate of $\mathrm{CO}_{2}$ assimilation rate has been established, i.e., a linear relation applies in many circumstances (van Keulen and Stol 1991). A high N fertility is expected to lead to an investment of $\mathrm{N}$ into $\mathrm{CO}_{2-}$ assimilating machinery and hence an increased $P_{\mathrm{N}}$ (Cechin 1998). However, the anticipated rise in photosynthetic functions are fulfilled only if the plant is supplied with sufficient water. In other words, $\mathrm{N}$ and water are known to interact in influencing plant growth and seed and dry mass production (Kiani et al. 2016). Even though suboptimal N concentrations are postulated to impose serious limitations to the photosynthetic functions and, subsequently, dry mass and seed yield production by modern varieties of many crop plants, some evidence suggests that this generalization may not be valid with less-developed ancient land races of some staple crops (Pourazari et al. 2015). Furthermore, lack of sufficient water for irrigation, in one hand, and environmental concerns, such as environmental pollution due to excessive use of $\mathrm{N}$, on the other, have inspired the quest for water- and $\mathrm{N}$-use efficient crop species.

Received 1 July 2017, accepted 27 September 2017, published as online-first 23 May 2018.

${ }^{+}$Corresponding author; phone: +98313 391 3459, fax: +98313 3913447, e-mail: ehsanzadehp@gmail.com

Abbreviations: ASW - available soil water; Cars - carotenoids; Chl - chlorophyll; $C_{\mathrm{i}}$ - intercellular $\mathrm{CO}_{2}$ concentration; $E$ - transpiration rate; $\mathrm{F}_{\mathrm{v}} / \mathrm{F}_{\mathrm{m}}$ - maximal quantum efficiency of PSII; $g_{\mathrm{s}}$ - stomatal conductance to the $\mathrm{CO}_{2}$; LAI - leaf area index; LSD - least significant difference; $M_{\mathrm{c}}$ - mesophyll conductance; modern wheats - free-threshing durum and bread wheats; MSI - membrane stability index; N - nitrogen; $P_{\mathrm{N}}$ - net photosynthetic rate; ROS - reactive oxygen species; SDM - plant aboveground dry mass; WUE - water-use efficiency; $\mathrm{WUE}_{\mathrm{i}}$ - intrinsic water-use efficiency.

Acknowledgements: Financial support for conducting this study has been granted by the Isfahan University of Technology, Isfahan, Iran. 
Emmer wheat (Triticum turgidum ssp. dicoccum) has played a main role as staple food crop of the ancient nations in the Old World for centuries (Arzani 2011). It is rather unfortunate that not so many farmers, nowadays, rely on this type of tetraploid wheat anymore. Judging from the declining trend in cultivation of this ancient wheat type (i.e., at least in the Middle East and the Fertile Crescent), it is imaginable that this species could face extinction and/or at least genetic erosion. In fact, there is still a considerable lack of knowledge concerning the impact of environmental constraints on physiological functions of this asset plant species. As it has been emphasized by Thormann et al. (2015), an effective mitigation of genetic erosion and conservation of genetic diversity in the face of the eminent global climatic change necessitates these landraces to be more seriously attended by the researchers. Interest in ancient species such as emmer wheat has been renewed due partly to the fact that

\section{Materials and methods}

Plant material and experiment set-up: A three-replicate split factorial experiment was conducted at the Lavark Research Farm of the Isfahan University of Technology, located in Najaf Abad $\left(32^{\circ} 32^{\prime} \mathrm{N}, 51^{\circ} 23^{\prime} \mathrm{E}, 1,630 \mathrm{~m}\right.$ a. s. 1., $14.5^{\circ} \mathrm{C}$ is mean annual temperature and $140 \mathrm{~mm}$ mean annual precipitation), central Iran, in 2015. A factorial of seven wheat genotypes, i.e., five emmer wheats (Joneghan, Zarneh, Singerd, Shahrekord, Khoygan), and two modern wheats (including Yavaroos free-threshing tetraploid durum wheat cultivar and Roushan free-threshing hexaploid bread wheat cultivar) along with two concentrations of soil-applied $\mathrm{N}$ fertilizer were assigned to subplots. The two concentrations of $\mathrm{N}$ were $30 \mathrm{~kg}(\mathrm{~N}) \mathrm{ha}^{-1}(\mathrm{~N}$-limited) and $100 \mathrm{~kg}(\mathrm{~N}) \mathrm{ha}^{-1}$ (N-sufficient) in the form of urea $(46 \% \mathrm{~N})$, where the first half of each $\mathrm{N}$ amount was applied at the seeding stage and the second half was top-dressed at the stem elongation. Healthy seeds of the wheat genotypes were sown $3-5 \mathrm{~cm}$ deep in $2 \times 4$ m plots in first week of November 2015, where each plot consisted of ten rows spaced $20 \mathrm{~cm}$ apart. Seeding rate was set to nearly 400 seeds $\mathrm{m}^{-2}$ in all experimental units. In order to assure uniform plant emergence and seedling establishment, all experimental units were irrigated uniformly twice, one immediately after sowing and the other at third week of November 2015. Plants were allowed to over-winter and undergo tillering throughout November 2015 to February 2016.

Implementation of irrigation treatment: Irrigation regimes were applied from March to June 2016. Irrigation after $30-40 \%$ depletion of soil moisture of the field capacity was chosen as stress-free control and irrigation after $60-70 \%$ depletion of soil moisture of the field capacity was considered as drought stress. Irrigation regimes were assigned to main plots. In order to carry out the above irrigation regimes, a moisture release curve was developed for the soil of the experimental field and these species are less-demanding at least in terms of $\mathrm{N}$ supply (Marino et al. 2016). Data on the interactive effect of $\mathrm{N}$ and water availability on growth, photosynthesis, and resource-use efficiency of different types of wheat is limited. There might be contrasts in terms of response to water and $\mathrm{N}$ supplies of emmer type of tetraploid wheat and the free-threshing tetra and hexaploid wheats (modern wheats). This study was, hence, carried out to dissect potentially different modifications in the photosynthetic functions of hulled emmer wheat and free-threshing durum and bread wheats (modern wheats) in response to $\mathrm{N}$ supplement and irrigation regimes. These potent differential photosynthetic and physiological responses of ancient emmer wheats may be implicated in efforts towards organic farming through lowering $\mathrm{N}$ fertilizer applications and quest for finding drought-tolerant genetic resources for our staple crop, i.e., wheat.

calculation of the available soil water and volume of irrigation water $\left(\mathrm{V}_{\text {irrg }}\right)$ were done based on Eq. (1) and (2) (Allen et al. 1998) according to the details given in Kiani et al. (2016) and Yousefzadeh Najafabadi and Ehsanzadeh (2017)

$\mathrm{ASW}=\left(\theta_{\mathrm{FC}}-\theta_{\mathrm{PWP}}\right) \times \mathrm{Bd} \times \mathrm{V}$

where $\theta_{\mathrm{FC}}$ is the gravimetric soil-water content (\%) at field capacity, $\theta_{\mathrm{PWP}}$ is the gravimetric soil-water content $(\%)$ at permanent wilting point, $\mathrm{Bd}$ is the bulk density of the soil $\left(\mathrm{g} \mathrm{cm}^{-3}\right)$, and $\mathrm{V}$ is the volume of soil layer in the root zone $\left(\mathrm{m}^{3}\right)$.

$\mathrm{V}_{\text {irrg }}=(\mathrm{ASW} \times \mathrm{f}) / \mathrm{E}_{\mathrm{a}}$

where $\mathrm{f}$ is the fraction of ASW depletion (60 and 80\%) from the root zone and $E_{a}$ is the percent of irrigation efficiency.

A volumetric counter was used for controlled delivering of water from a pumping station to plots of each irrigation level via polyethylene pipe. Drip-tapes $(16 \mathrm{~mm}$ diameter) containing drippers, which were spaced $15 \mathrm{~cm}$ apart, were installed alongside each row of planting. Flow rate for each dripper was maintained at $1.3 \mathrm{~L} \mathrm{~h}^{-1}$. Drip-tape spacing was $0.75 \mathrm{~m}$, the access tubes were installed at a distance of 5-10 cm from the drip-tape. Irrigation started as soon as either $30-40$ or $60-70 \%$ of the total available water was depleted in the root zone, for control and drought stress, respectively. The irrigation depth for the both control and drought type of irrigation treatment was calculated based on the amount of water required to replenish soil water depletion to the field capacity point.

Photosynthetic attributes and water-use efficiency: $\mathrm{Chl} a, \mathrm{Chl} b$, and carotenoids (Car) concentrations were measured on the fresh leaf samples taken at anthesis according to the procedure described in Lichtenthaler and 
Buschmann (1994) and the details given by Yousefzadeh Najafabadi and Ehsanzadeh (2017). In brief, $0.2 \mathrm{~g}$ of samples were milled and extracted in $10 \mathrm{~mL}$ of $80 \%(\mathrm{v} / \mathrm{v})$ acetone and absorbances at 470, 646, and $663 \mathrm{~nm}$ (for $\mathrm{Chl} a$, Chl $b$, and Cars, respectively) were measured by a spectrophotometer (U 1800, HITACHI, Japan) and the results expressed as $\mathrm{mg} \mathrm{g}^{-1}$ (leaf fresh mass, FM). Maximal quantum efficiency of PSII $\left(\mathrm{F}_{\mathrm{v}} / \mathrm{F}_{\mathrm{m}}\right)$ was assessed at anthesis using healthy, mature, and dark-adapted leaves. To accomplish this, three measurements per experimental unit were carried out between 10:00 to $12: 00 \mathrm{~h}$ on the leaves, which were dark-adapted for nearly 20 min using a portable Chl fluorometer (Opti-Sciences, Inc., Hudson, $\mathrm{NH}$, USA) and a mean of the three measurements were used for each plot. Gas-exchange attributes, $P_{\mathrm{N}}$, intercellular $\mathrm{CO}_{2}$ concentration $\left(C_{\mathrm{i}}\right), g_{\mathrm{s}}$ and transpiration rate $(E)$ were measured at anthesis using three measurements per experimental unit. Measurements were carried out between 10:00 to 12:00 h using a calibrated portable gas-exchange system ( $L C i$, ADC Bioscientific Ltd., UK). Intrinsic photosynthetic water-use efficiency $\left(\mathrm{WUE}_{\mathrm{i}}\right)$ for all experimental plots were estimated by dividing $P_{\mathrm{N}}$ to $g_{\mathrm{s}}$. Mesophyll conductance $\left(\mathrm{M}_{\mathrm{c}}\right)$ was estimated by dividing $P_{\mathrm{N}}$ to $C_{\mathrm{i}}$.

Membrane stability index and plant above ground dry mass: For measuring membrane stability index (MSI), leaf

\section{Results}

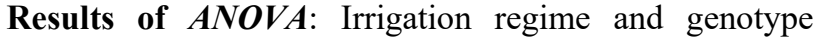
affected all measured photosynthetic attributes, but $\mathrm{N}$ application only affected $\mathrm{Chl}$ and gas-exchange attributes (Table 1). Interaction of genotype $\times$ irrigation was statistically significant for all measured traits with the exception of $C_{\mathrm{i}}, \mathrm{MSI}$, and $\mathrm{F}_{\mathrm{v}} / \mathrm{F}_{\mathrm{m}}$. Interaction of $\mathrm{N} \times$ genotype was statistically significant for all measured traits with the exception of $C_{\mathrm{i}}$, Chl $a$, and Chl $a / b$. Emmer group of wheats differed significantly from the modern group in terms of all attributes examined, except for $\mathrm{WUE}_{\mathrm{i}}, \mathrm{Chl} a / b$, and $\mathrm{M}_{\mathrm{c}}$. Interaction of irrigation $\times$ group was statistically significant for all traits with the exception of $E, \mathrm{MSI}_{\mathrm{c}} \mathrm{M}_{\mathrm{c}}$, and $\mathrm{F}_{\mathrm{v}} / \mathrm{F}_{\mathrm{m}}$. Interaction of $\mathrm{N} \times$ group was statistically significant only for $P_{\mathrm{N}}, g_{\mathrm{s}}, \mathrm{WUE}_{\mathrm{i}}, \mathrm{Chl} b$, and Car. Interaction of irrigation $\times \mathrm{N}$ was statistically significant only for $P_{\mathrm{N}}, \mathrm{MSI}, \mathrm{WUE}$, and SDM.

Response of emmer and modern wheats to drought: $P_{\mathrm{N}}$, $E, g_{\mathrm{s}}, C_{\mathrm{i}}, \mathrm{MSI}$, and $\mathrm{M}_{\mathrm{c}}$ decreased in the emmer and modern wheats, but the decreases in Chl $a$, Chl $b$, and Car of drought-stressed emmer wheat group were smaller than those of the modern wheats (Table 2). In fact, despite notable drought-induced decreases in concentration of all photosynthetic pigments, e.g., $\mathrm{Chl} a, \mathrm{Chl} b$, and Car and MSI in the two modern wheats, no notable decreases were observed in those of drought-induced emmer wheat plants. $\mathrm{WUE}_{\mathrm{i}}$ and $\mathrm{Chl} a / b$ of drought-stressed plants of both wheat discs of at least $200 \mathrm{mg}$ were obtained at anthesis and immersed in two series of tubes containing $10 \mathrm{~mL}$ of double-distilled water. While the first series of tubes were maintained in a hot water bath at $40^{\circ} \mathrm{C}$ for $30 \mathrm{~min}$, the other series were kept at $100^{\circ} \mathrm{C}$ for $10 \mathrm{~min}$. Electrical conductivity of samples was measured with EC meter (Model Cyberscan, Singapore). The MSI was calculated according to Bajji et al. (2002). Plant above ground dry mass (SDM) was determined at physiological maturity (i.e., late June 2016) using samples harvested from the second and third rows of each plot. The samples were dried at $68^{\circ} \mathrm{C}$ for $72 \mathrm{~h}$, weighed and expressed as $\mathrm{g} \mathrm{m}^{-2}$.

Statistical analysis: Data were subjected to an analysis of variance (ANOVA) using Statistical Analysis Software (SAS Institute Inc., Version 9.1, Cary, North Carolina, USA). For those statistical tests, where $F$-tests were found significant, means were separated using least significant difference (LSD) procedure at 0.05 level of probability. Orthogonal contrasts were developed for comparing the emmer group of five tetraploid wheats (i.e., Joneghan, Ozonblagh, Singerd, Shahre-kord, Khoygan) against the modern group of two free-threshing wheats (i.e., Roushan hexaploid bread wheat and Yavaroos tetraploid durum wheat). Interacting effects of these two groups of wheat with irrigation and $\mathrm{N}$ regimes were also examined.

types increased, compared to non-stressed plants, but the extent of increases was greater for the modern wheats. Both emmer and modern wheat groups shared the same trend in a decrease of $F_{v} / F_{m}$ due to drought, but the extent of the decrease was greater in the modern wheats. While non-stressed modern wheats out-yielded the emmer wheat group in terms of SDM, these attributes in both wheat types decreased at the presence of drought. Albeit, the magnitude of the decreases for modern wheats was substantially greater than that for the emmer group of wheat.

Response of emmer and modern wheats to $\mathrm{N}$ supply: Even though $\mathrm{N}$ application led to small increases in $P_{\mathrm{N}}$ of both wheat types, the increase was greater in the emmer wheat group, relative to the modern wheat group (Table 3). No notable $\mathrm{N}$-induced changes were observed in other gasexchange attributes (e.g., $C_{\mathrm{i}}, E$, and $\mathrm{M}_{\mathrm{c}}$ ) of both wheat types. Albeit, $g_{s}$ of the emmer wheats remained unchanged, that of the modern wheats decreased with increase in $\mathrm{N}$ application. Emmer group of wheat contrasted the modern group in terms of $\mathrm{N}$-induced modifications in $W_{U}$. Sufficient $N$ led to a decrease in $W_{U} E_{i}$ of the emmer wheats, but it led to an increase in that of the modern wheats. Sufficient concentration of $\mathrm{N}$ fertilizer led to an increase in $\mathrm{Chl} a$ and $\mathrm{Chl} b$ concentrations in both wheat types, but the extent of the increases was smaller in 


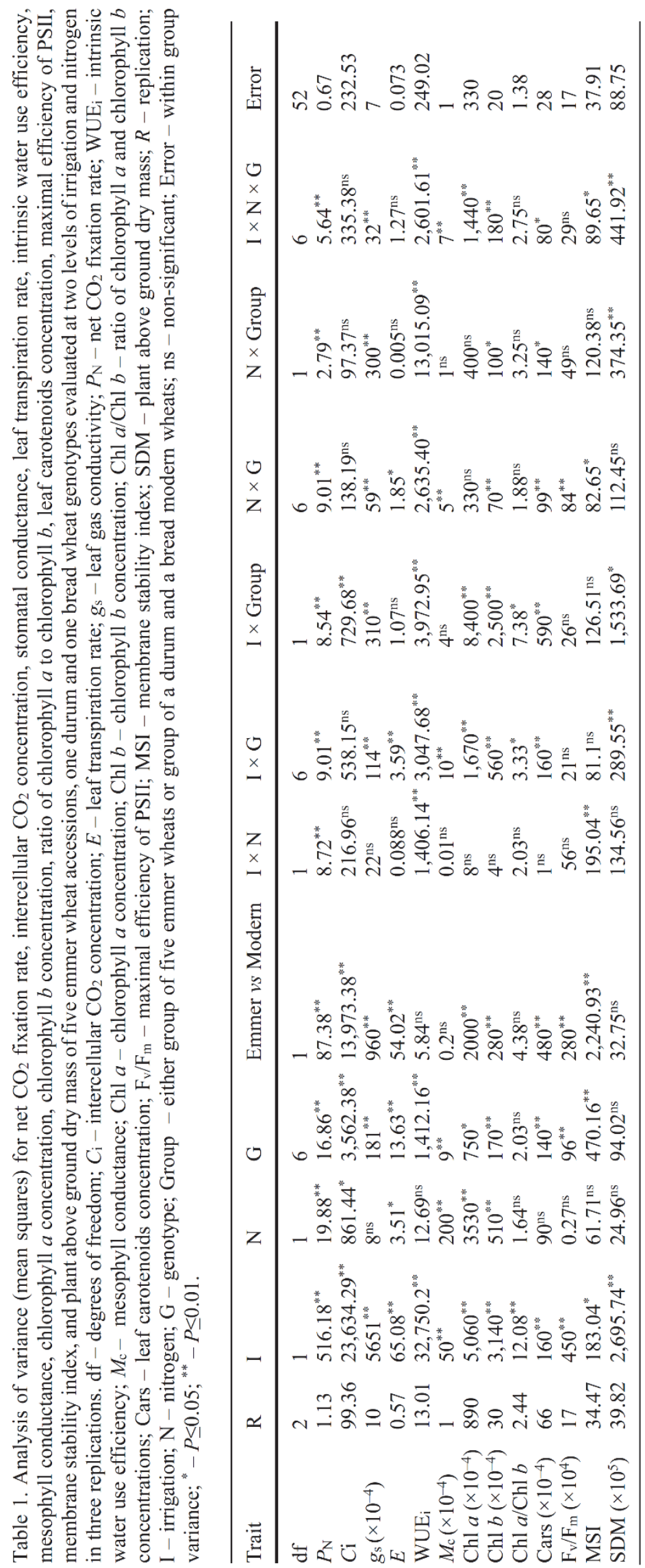




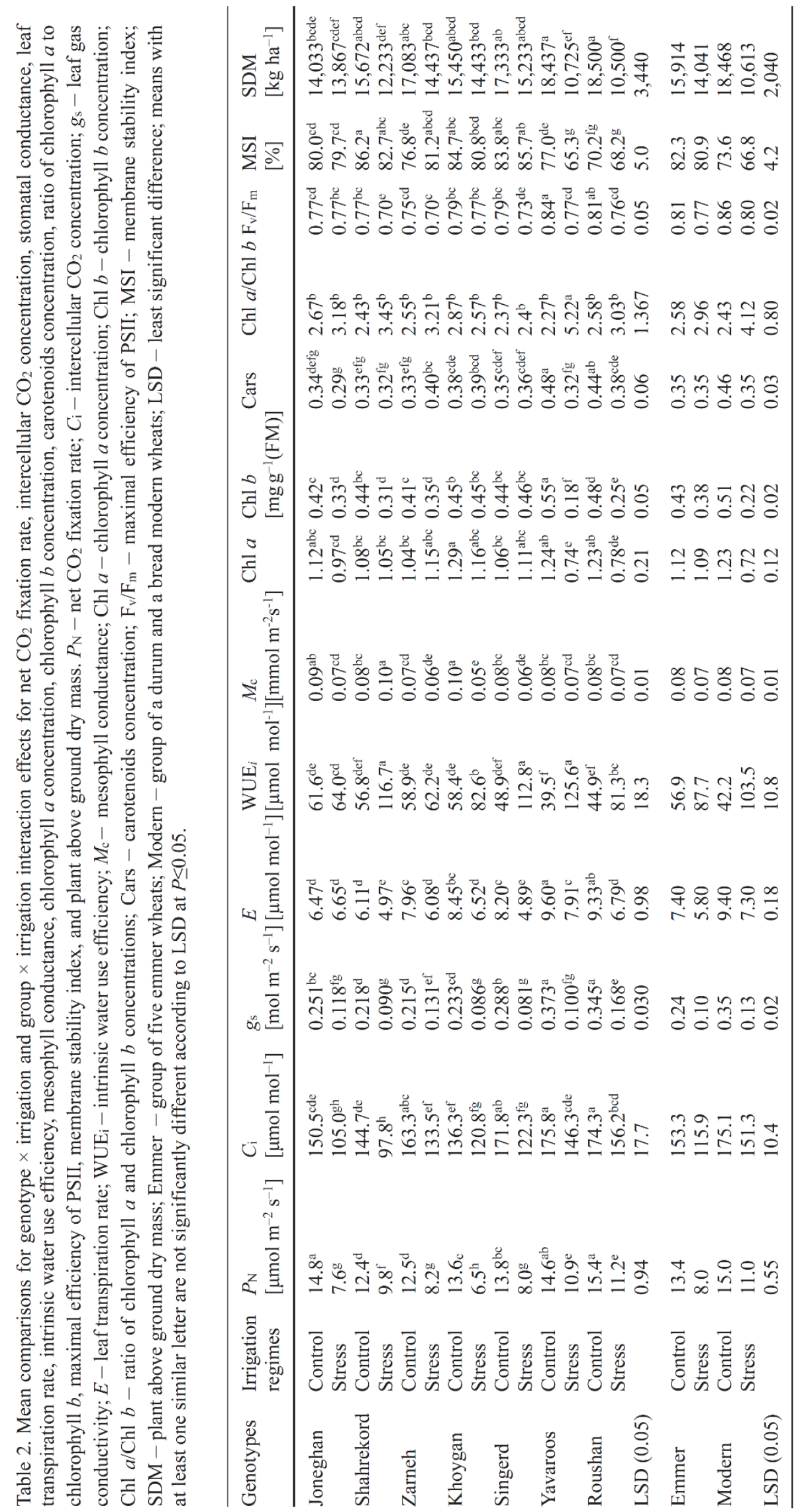


Table 3. Mean comparisons for nitrogen $\times$ irrigation interaction effect for net $\mathrm{CO}_{2}$ fixation rate, membrane stability index, intrinsic water-use efficiency and plant above ground dry mass. LSD - least significant difference; MSI - membrane stability index; $P_{\mathrm{N}}-$ net $\mathrm{CO}_{2}$ fixation rate; SDM - plant above ground dry mass; $\mathrm{WUE}_{\mathrm{i}}$ - intrinsic water-use efficiency; means with a similar letter are not significantly different according to LSD at $P \leq 0.05$.

\begin{tabular}{llllll}
\hline Irrigation regimes & $\begin{array}{l}\text { Nitrogen } \\
{\left[\mathrm{kg} \mathrm{ha}^{-1}\right]}\end{array}$ & $\begin{array}{l}P_{\mathrm{N}} \\
{\left[\mu \mathrm{mol} \mathrm{CO} \mathrm{C} \mathrm{m}^{-2} \mathrm{~s}^{-1}\right]}\end{array}$ & $\begin{array}{l}\mathrm{MSI} \\
{[\%]}\end{array}$ & $\begin{array}{l}\mathrm{WUE}_{\mathrm{i}} \\
{\left[\mu \mathrm{mol} \mathrm{CO}_{2} \mathrm{~mol}^{-1} \mathrm{H}_{2} \mathrm{O}^{-1}\right]}\end{array}$ & $\begin{array}{l}\mathrm{SDM} \\
{\left[\mathrm{kg} \mathrm{ha}^{-1}\right]}\end{array}$ \\
\hline Control & 30 & $13.0^{\mathrm{b}}$ & $80.5^{\mathrm{a}}$ & $48.2^{\mathrm{b}}$ & $16,071^{\mathrm{a}}$ \\
& 100 & $14.7^{\mathrm{a}}$ & $79.1^{\mathrm{a}}$ & $57.2^{\mathrm{b}}$ & $17,217^{\mathrm{a}}$ \\
Water-deficit stress & 30 & $8.7^{\mathrm{c}}$ & $74.5^{\mathrm{b}}$ & $95.9^{\mathrm{a}}$ & $13,289^{\mathrm{b}}$ \\
& 100 & $9.1^{\mathrm{c}}$ & $79.2^{\mathrm{a}}$ & $88.5^{\mathrm{a}}$ & $12,833^{\mathrm{b}}$ \\
LSD $(0.05)$ & & 0.5 & 3.8 & 9.7 & 1,934 \\
\hline
\end{tabular}

the emmer group of wheats, in comparison to the modern wheat group. Though, no notable $\mathrm{N}$ application-associated changes were observed in $\mathrm{Chl} a / b, \mathrm{~F}_{\mathrm{v}} / \mathrm{F}_{\mathrm{m}}$, and Car concentration of the examined wheats of both types. Contrasting responses to $\mathrm{N}$ application were noted between the two groups of wheat in terms of SDM. Despite a decrease of $750 \mathrm{~kg} \mathrm{ha}^{-1}$ in SDM of the emmer wheat group, an increase of $2470 \mathrm{~kg} \mathrm{ha}^{-1}$ was observed in the modern wheats, when exposed to the sufficient $\mathrm{N}$ content.

\section{Discussion}

Reduced water uptake, i.e., under drought-stress conditions, results in a decrease in tissue water content and cell turgor. Therefore, cell elongation in water-deprived plants is inhibited by the reduced turgor pressure. Likewise, drought stress also trims down photoassimilation and availability of metabolites required for cell division. As a consequence, impaired mitosis, cell elongation and expansion result in suppressed plant growth functions, including plant height and leaf area (Farooq et al. 2009). Indeed, a primary plant response to water deficit is a restriction of leaf growth and expansion (Guo et al. 2007), attributing to the suppression of foliar expansion and the subsequent photosynthetic functions. In fact, nearly every plant function could be affected by drought stress. Among these traits, plant phenology and growth attributes, leaf relative water content, leaf area and photosynthetic components, cell membrane stability, and antioxidative enzymes activities could be mentioned (Askari and Ehsanzadeh 2015). Environmental constraints such as drought may restrict photoassimilatory activities and whole plant photosynthesis, through stomatal and mesophyll limitations (Živčák et al. 2014), degrading Chl, limiting leaf area expansion, and/or accelerating senescence processes, leading to the lowering of both SY and SDM. In a whole plant scale, however, the carbon economy is known to be related to the $\mathrm{N}$ economy (Pan et al. 2011).

In the present study, drought-induced decreases in Chl $a$ were nearly 5 and $45 \%$ in the emmer and modern groups of wheat, respectively (data not shown), and those in Chl $b$ were in the range of 12 and $58 \%$ for these groups of wheat, respectively. It seems, therefore, that the photosynthetic pigments were a prime target of harmful effects of water
Response to $\mathrm{N}$ supply under different irrigation regimes: Sufficient $\mathrm{N}$ led to increase in $P_{\mathrm{N}}$ of examined wheats only at the absence of drought, i.e., droughtstressed plants did not respond to $\mathrm{N}$ fertilization (Table 4). While non-stressed plants indicated increases in $\mathrm{WUE}_{\mathrm{i}}$ and SDM in response to sufficient $\mathrm{N}$ fertilization, the droughtstressed plants did not indicate such responses; they tended to indicate decreases in $\mathrm{WUE}_{\mathrm{i}}$ and SDM at the presence of sufficient $\mathrm{N}$.

deprivation, at least in the modern genotypes. Considering the drought-induced increase in mean $\mathrm{Chl} a / b$, preferential decrease in the $\mathrm{Chl} b$ during the exposure of emmer and modern wheats to drought could be proposed as a speculative model for the evident modifications in leaf Chl concentration of the wheat plants in the present study. A more plausible explanation for the preferential loss of Chl $b$ in the presence of drought is the conversion of $\mathrm{Chl} b$ to $\mathrm{Chl}$ $a$. Given the increase in $\mathrm{Chl} a / b$ concomitant with decreases in Chl concentration in drought-stressed wheat plants, it seems that a part of the damage to Chl $a$ was compensated for by the conversion of $\mathrm{Chl} b$ to $\mathrm{Chl} a$. Further evidence for harmful consequences of drought to the photosynthetic functions could be drawn in from measuring on photosynthetic electron transfer chain, e.g., PSII functionality. Nonphotochemical quenching could be imagined as a safety valve to dissipate the excess light energy (i.e., in the form of heat) created in chloroplast electron transfer chain during stressful conditions. Even though much of this excess energy is dissipated in reaction center of PSII, protective role of cyclic electron transfer in PSI may not be underestimated (Živčák et al. 2014). As it has been suggested by the literature (Breštič et al. 2015), PSII is responsible for effective photoprotecting of entire photosynthetic electron transfer chain in chloroplasts. $\mathrm{F}_{\mathrm{v}} / \mathrm{F}_{\mathrm{m}}$ is a measure of the maximum efficiency of PSII, i.e., the quantum efficiency of PSII if all its centers were open. In our experiment, drought-associated significant decreases in the $\mathrm{F}_{\mathrm{v}} / \mathrm{F}_{\mathrm{m}}$ of dark-adapted plants were recorded, indicating that photosynthetic electron transfer in both groups of wheat suffered from the stress. Albeit, droughtinduced decreases in $F_{v} / F_{m}$ were not substantial, 


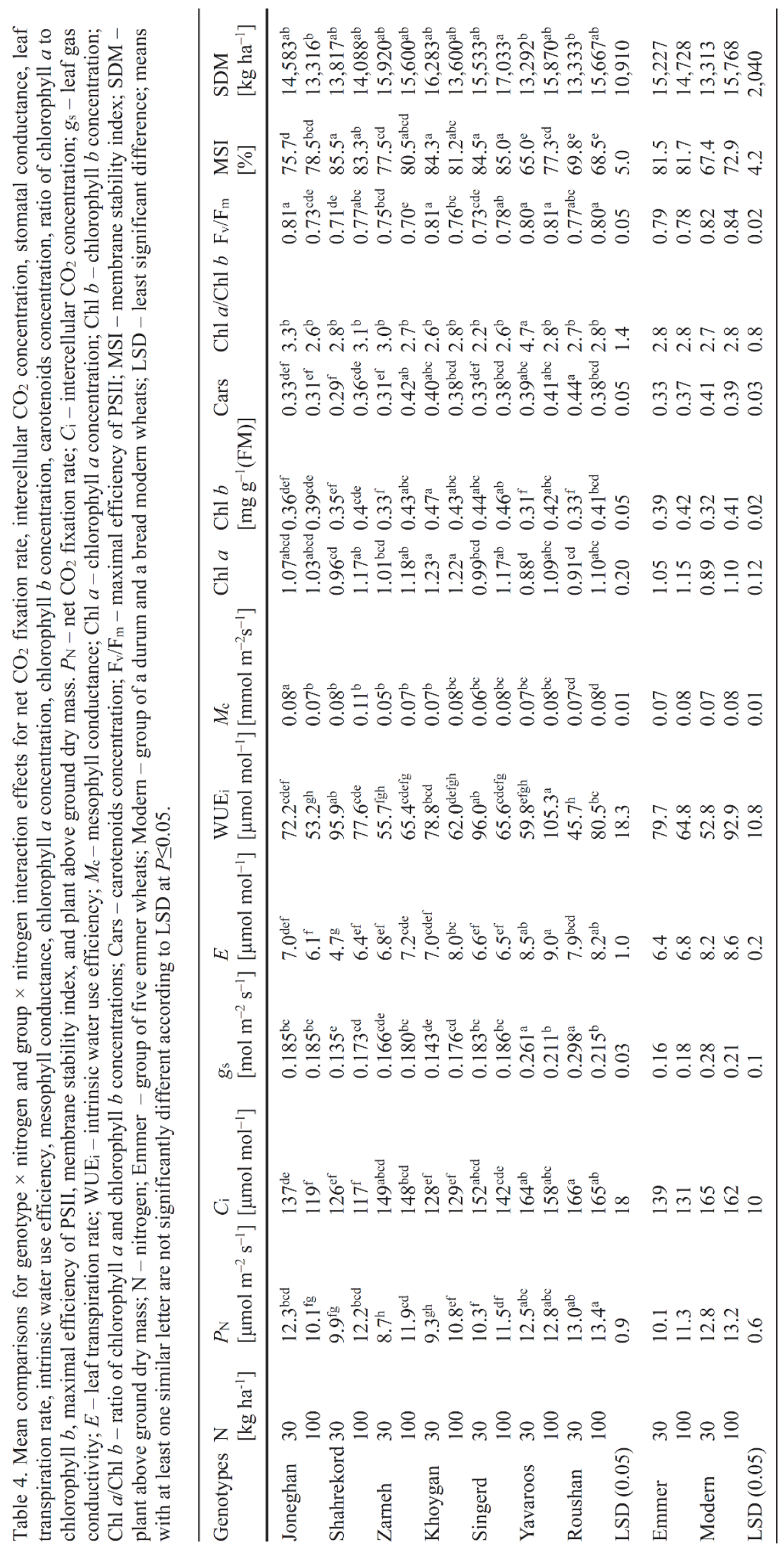


confirming the previously reported (Živčák et al. 2014) relative resistance of PSII photochemistry (as compared to $\mathrm{CO}_{2}$ assimilation) to moderate drought stress. It is believed that utilization of electrons for enhanced photorespiration in stressed plants is the main reason behind the above mentioned resistance of electron transfer rate against prolonged moderate drought stress.

Magnitude of alteration in $C_{\mathrm{i}}$ can be taken as a marker for the involvement of stomatal closure in the depression of photosynthetic capacity of stressed plants (Seemann and Critchley 1985). Increases in $C_{\mathrm{i}}$, concomitant to stomatal closure, are interpreted as indications of drought-induced damages to the photosynthetic apparatus (Zhang et al. 2015). However, a decreased $g_{\mathrm{s}}$ in drought-stricken plants of the present work was not associated to such increases in $C_{\mathrm{i}}$, indicating that perhaps photosynthetic machinery was not seriously damaged by the stress. Stomatal closure brings about leaf heating (Venora and Calcagno 1991) while stomatal opening, which is reflected in an increased $g_{s}$, is, often, accompanied by a depression in canopy temperature and an enhancement of the photosynthetic rate and grain yield (Fischer et al. 1998). Stress-induced alterations in status of plant growth regulators, such as ethylene, auxin, and abscisic acid and, thereby, stomatal movements altogether are parts of a general acclimation strategy and may be attributed to a morphogenic response that is evoked by distinct sub-lethal stresses (Potters et al. 2007). In fact, $g_{\mathrm{s}}$ is known to be the most sensitive plant gas-exchange attribute upon confronting drought. It is postulated that this sensitivity is related to stress-induced increases in xylem abscisic acid concentration (Liu et al. 2005). We observed that drought-driven decreases in $P_{\mathrm{N}}$ were in the range of $26 \%$ (i.e., in the modern wheats) to $40 \%$ (i.e., in the emmer wheats), when correspondent decreases in $g_{\mathrm{s}}$ were within the $58-63 \%$ range. As it has been documented in the literature (Fischer et al. 1998), over the course of plant breeding $C_{\mathrm{i}}, g_{\mathrm{s}}, E$, and $P_{\mathrm{N}}$ of wheat genotypes have improved, leading to a greater seed yield in the more recently released cultivars of wheat. In the present study, emmer wheat group were notably outperformed by the modern wheats in terms of the grain yield, but contained a greater amount of protein in their grains, irrespective of water and $\mathrm{N}$ supply (data not shown). The overall greater mean $C_{\mathrm{i}}, P_{\mathrm{N}}, \mathrm{F}_{\mathrm{v}} / \mathrm{F}_{\mathrm{m}}$, and more notably $g_{\mathrm{s}}$ and grain yield of the so-called modern wheats, compared to the primitive emmer wheats of the present study did not come as a surprise. In fact, it is known that cereal crops breeding for higher grain yield in the past decades have been concomitant to increase in $g_{\mathrm{s}}$ (Araus et al. 2002). In the present study, there was a tendency in the emmer group of wheats to maintain their photosynthetic pigments, irrespective of water and $\mathrm{N}$ supply. On the other hand, the notable decreases in $P_{\mathrm{N}}$ of the stressed plants of both groups of wheat indicate that the photosynthetic activity of both groups of wheat was disrupted by water deprivation (Table 2). A $10-13 \%$ decrease in $\mathrm{M}_{\mathrm{c}}$ of the water-deprived plants along with the somewhat small decrease in $C_{\mathrm{i}}$ might be taken as evidence for certain degrees of stress-induced damage to the chloroplasts. It has been established that drought-associated decreases in crop yield are consequent to depressions in leaf area expansion, rather than to lowering of photosynthetic rate per se (Araus et al. 2002). Available literature indicates that adverse impacts of water stress on photosynthetic rate are attributable to certain disorders at different structuralfunctional levels, e.g., altering chloroplast ultrastructure, lowering Chl content, and depressing the activity of key photosynthetic enzymes, such as Rubisco (Zhang et al. 2015). In the event of moderate drought stresses that lead to relatively small decreases in relative water content, decreases in $g_{\mathrm{s}}$ are mainly responsible for decreases in actual $P_{\mathrm{N}}$ and potential $P_{\mathrm{N}}$ (Lawlor and Cornic 2002). According to this notion, these $g_{\mathrm{s}}$-related decreases in $\mathrm{CO}_{2}$ assimilation are restored by elevating $\mathrm{CO}_{2}$ concentration, and metabolic inhibitions in photosynthetic activity, which are subsequent to decreases in ATP and Rubisco synthesis, occur only following true stress and hence serious decreases in relative water content. Moreover, the droughtinduced decreases in $P_{\mathrm{N}}$ are often related to decreases in carboxylation efficiency through lowering specific activity of Rubisco rather than to decreases in the amount of this enzyme (Ögren 1988).

Drought stress-initiated stomatal closure leads to the cessation of $\mathrm{CO}_{2}$ fixation and the subsequent limitation of $\mathrm{NADP}^{+}$, resulting in electron transfers to oxygen and, thus, accumulation of superoxide and hydrogen peroxide. This may initiate disruptions in the activity of some scavenger enzymes of reactive oxygen species (ROS) (e.g., catalase) and, hence, increase in lipid peroxidation and damage to Chl and cellular membranes (Shao et al. 2005). Stress-induced structural damage to membrane and, in turn, decrease in MSI has been reported as a common response to environmental constraints, including drought stress. Water stress may, therefore, modify the chemical composition and physical structure of biological membranes and, as a result, the rate of electrolyte leakage. The extent of membrane damage by adverse environmental conditions is used as a measure of stress tolerance, i.e., the degree of membrane injury could be a good measure for plant tolerance to drought stress (Gadallah 1995). Emmer wheats tended to maintain their MSI under different moisture conditions, in contrast to a notable decrease in MSI of the drought-stressed modern wheats (Table 2). We did not attempt assessing ROS content and antioxidative activities, but from the smaller decreases in concentration of photosynthetic pigments and MSI, it may be inferred that the emmer group of wheats was able to protect subcellular and cellular membranes from a presumed drought-induced oxidative damage. Genotypic-specificity of drought-associated membrane damages have been confirmed by other researchers (e.g., Shao 2005).

WUE is a measure of photosynthetically assimilated carbon in the expense of water lost through transpiration 
(Flexas et al. 2010) and photosynthetic water-use efficiency could be represented either as the ratio between $P_{\mathrm{N}}$ and the water lost in transpiration (i.e., instantaneous water-use efficiency) or the ratio between $P_{\mathrm{N}}$ and the $g_{\mathrm{s}}$ (i.e., intrinsic water-use efficiency). The intrinsic photosynthetic $\mathrm{WUE}_{\mathrm{i}}$ was assessed in the present work. Our data are in line with other reports (Liu et al. 2005), as we found that $\mathrm{WUE}_{\mathrm{i}}$ of the examined wheats increased with water limitation. The evidently greater increase in $\mathrm{WUE}_{\mathrm{i}}$ of the drought-stressed modern wheats was due, primarily, to the notably smaller decrease in $P_{\mathrm{N}}$ of the latter wheats, compared to the emmer wheats (Table 2). It is admitted that it is not strait forward to make inferences based on leaf-level $W E_{i}$ to explain WUE at a whole-plant scale (Medrano et al. 2015), but the overall greater mean $\mathrm{WUE}_{\mathrm{i}}$ of the stressed emmer and modern wheats is potent to be taken as a promising perspective for improving WUE at the canopy level. The greater sensitivity of $g_{\mathrm{s}}$ to water limitation is said to be related to the fact that $g_{\mathrm{s}}$ is chiefly controlled by ABA synthesis in plant roots. Furthermore, a greater sensitivity of $g_{\mathrm{s}}$ and hence $E$ to water deficit, compared to $P_{\mathrm{N}}$, of the examined wheats agrees with the report of Flexas et al. (2010). Increases in $\mathrm{WUE}_{\mathrm{i}}$ with water deprivation in the examined plants were not far from our expectation, as such increases have been reported by the researchers working on different plant species (Medrano et al. 2015). It seems that the above correlative association holds true at least under moderate drought stresses. Part of the notable differences in $\mathrm{WUE}_{\mathrm{i}}$ between the two groups of the wheats can be explained by the fact that $\mathrm{WUE}_{\mathrm{i}}$ tends to vary due to an array of factors, including plant growth stage, leaf position, and time of the day at which measurements on $P_{\mathrm{N}}$ and $g_{\mathrm{s}}$ have been conducted.

$\mathrm{N}$ supply is known to add on a number of plant physiological attributes, including Chl concentration, $P_{\mathrm{N}}$, quantum yield, light-compensation point, free proline content, SDM, and the activity of antioxidative enzymes (Robinson and Burkey 1997, Zhao and Liu 2012). $P_{\mathrm{N}}$ often shows a positive correlation with leaf $\mathrm{N}$ content (Zhao and Liu 2012) and, hence, any serious reduction in plant $\mathrm{N}$ content (e.g., due to insufficient $\mathrm{N}$ supply) is likely to depress plant photosynthetic activity (Ashraf et al. 2002). Thus, $\mathrm{N}$ availability often affects $P_{\mathrm{N}}$ at the leaf and plant level as well as ecosystem level (Chapagain and Riseman 2015). Photosynthetic carbon reduction of the $\mathrm{C}_{3}$ plants is expected to be depressed in response to $\mathrm{N}$ deficiency, mainly because this deficiency leads to a lowered partitioning of the plant $\mathrm{N}$ to the synthesis of key enzymes such as Rubisco and chloroplast pigments (Robinson and Burkey 1997, Prsa et al. 2007). N deficiency may render plants sensitive to drought (Ögren 1988) but since $\mathrm{N}$ supplement has been reported to increase $P_{\mathrm{N}}$ and $g_{\mathrm{s}}$, drought-induced decreases in the above photosynthetic attributes are often counterbalanced, in part, by $\mathrm{N}$ supply (Cechin 1998). In the present study, the $\mathrm{N}$-induced increase in mean $P_{\mathrm{N}}$ was evident only at the absence of drought. Nitrogen supplement did not seem helpful in overcoming drought effects on the photosynthesis of the studied wheat genotypes; water-deprived wheat plants underwent a more notable depression in $P_{\mathrm{N}}$ and hence SDM, when they received sufficient N (Table 3). Moreover, the $\mathrm{N}$-associated insignificant modifications in some of the photosynthetic attributes (e.g., $P_{\mathrm{N}}, C_{\mathrm{i}}, E$, and $\mathrm{M}_{\mathrm{c}}$ ) were more or less alike in the emmer and modern wheats, but modifications in the rest of such attributes as $g_{\mathrm{s}}, \mathrm{WUE}_{\mathrm{i}}$, Car, and $\mathrm{F}_{\mathrm{v}} / \mathrm{F}_{\mathrm{m}}$ were rather contradictory (though, mainly insignificant) in these two groups of wheat (Table 4). In agreement with our data, lack of association between gasexchange attributes and plant $\mathrm{N}$ status has been confirmed by some reports (Ögren 1988). Even though it has been argued in the literature (e.g., Marino et al. 2016) that $\mathrm{N}$ supplement may enhance plant photosynthetic activity through an upregulation of synthesis of the enzyme Rubisco, our data are suggestive of a fair degree of proportionality in $\mathrm{N}$-induced improvements in $P_{\mathrm{N}}, \mathrm{M}_{\mathrm{c}}$, and leaf $\mathrm{Chl}$ concentration. We did not attempt to measure Rubisco activity, but from our measurements on an array of photosynthetic attributes, we are confident that $\mathrm{N}$ supplement led, at least in part, to the enhancement of photosynthesis in the examined wheats through increase in the Chl concentration. A general response of different planta to water and $\mathrm{N}$ deficits is an accelerated senescence of leaves that is, often, manifested as Chl loss. The effectiveness of $\mathrm{N}$ amendment on photosynthesis may vary with edaphic and climatic conditions, species, genotype, and developmental stage of the plant (Prsa et al. 2007). Therefore, the interactive effects of irrigation regime and $\mathrm{N}$ fertilizer observed with the emmer and modern wheats is not surprising (Table 3). Water limitation in arid and semi-arid regions and/or drought-stressed field crops is, often, concomitant to $\mathrm{N}$ deficiencies (Wu et al. 2009) and it may necessitate $\mathrm{N}$ fertilization. It has been estimated that worldwide $\mathrm{N}$ fertilizer application has increased 20-fold over the past half a century and the majority of the $\mathrm{N}$ supplement (e.g., 50-70\%) is not used by the plant, instead it is lost to deteriorate the environment (Lea and Azevedo 2006, Andrews and Lea 2013). It is, therefore, very interesting (at least from an environmental point of view) that these ancient emmer wheat genotypes are capable of maintaining their photosynthetic pigments and SDM at Ndeficient circumstances. It could be surmised that the existing pool of leaf $\mathrm{N}$ in $\mathrm{N}$-limited plants of these primitive wheats has sufficed Rubisco activity and efficiency. In the present study, the $P_{\mathrm{N}}$ and $g_{\mathrm{s}}$ of both groups of wheat were positively related. As it has been argued in a number of reports (e.g., Ashraf et al. 2002), if the $P_{\mathrm{N}}$ was solely dependent on the stomatal closure, $C_{\mathrm{i}}$ is expected to be lower in leaves of plants subjected to low $\mathrm{N}$ concentrations. But it is evident from the data of $C_{\mathrm{i}}$ that none of the $\mathrm{N}$ concentrations affected intercellular $\mathrm{CO}_{2}$ concentration (Table 4). This indicates a decrease in carbon fixation by the chloroplasts and also suggests that $g_{\mathrm{s}}$ was not the principal factor affecting photosynthesis. 
Another interesting finding of the present study was that in contrast to modern wheats, emmer wheats tended to maintain their $\mathrm{Chl}$ concentration despite considerable variation in water (Table 2 ) and $\mathrm{N}$ (Table 4) availability. It was also interesting that $\mathrm{N}$ and moisture level-related variations in the $P_{\mathrm{N}}$ of the modern wheats were not as great as the variations in their $\mathrm{Chl}$ concentration. Some reports hypothesized that photosynthetic electron transport chains per unit $\mathrm{Chl}$ in the chloroplast thylakoids of N-deprived leaves may be more concentrated than in chloroplasts of $\mathrm{N}$-supplied plant leaves (Robinson and Burkey 1997). This hypothesis might apply for the modern wheats of the present experiment. In fact, some plant species may undergo a preferential partitioning of leaf $\mathrm{N}$ to thylakoids as a strategy to survive prolonged $\mathrm{N}$ deprivations via maintaining photosynthetic electron transport per unit Chl. Positive correlative associations between $\mathrm{N}$ supplement (and hence leaf $\mathrm{N}$ ), Chl $a$, and in a lesser extent $\mathrm{Chl} b$ concentrations, have been confirmed in diverse plant species, such as the $\mathrm{C}_{4}$ annual cereal maize (Ercoli et al. 1993) and the $C_{3}$ tree apple (Prsa et al. 2007) species. A maintained $\mathrm{WUE}_{\mathrm{i}}$ of emmer and modern wheats despite contrasting $\mathrm{N}$ supplies in the present study was mainly due to the same increase in $P_{\mathrm{N}}$ and $g_{\mathrm{s}}$ in the N-supplemented plants. Improvement in the WUE of wheat due to an enhanced soil $\mathrm{N}$ status (e.g., via intercropping wheat with legume crops) has been documented (Chapagain and Riseman 2015).

Even though reports on negative effect of $\mathrm{N}$ supply on Chl, leaf area, $P_{\mathrm{N}}$, and, thus, SDM of some bread wheat genotypes are not scarce (Ashraf et al. 2002), beneficial effects of $\mathrm{N}$ supply on $\mathrm{Chl}$ content, $P_{\mathrm{N}}$, and, hence, grain yield of bread wheat have been also documented (Ashraf et al. 2002). With the literature available and the data gathered in this study, it is not easy to explain the response of the examined emmer wheats to the $\mathrm{N}$ supply. For example, our results are in contradiction with those of Marino et al. (2016); they reported positive effects of $\mathrm{N}$ supply on the yield of emmer wheat. Moreover, in the latter study, $\mathrm{N}$-induced enhancements in gas-exchange attributes were consistent with the increases in yield of the Italian emmer wheat accessions, which contradicts our findings on the Iranian emmer wheats. The negative response of emmer wheats to $\mathrm{N}$ supply can be partially related to earlier findings showing lack of ability to

\section{References}

Allen R.G., Pereira L.S., Raes D. et al.: Crop Evapotranspiration: Guidelines for Computing Crop Water Requirements. FAO Irrigation and Drainage Paper. Pp. 56. FAO, Rome 1998.

Andrews M., Lea P.J.: Our nitrogen 'footprint': the need for increased crop nitrogen use efficiency. - Ann. App. Biol. 163: 165-169, 2013.

Arzani A.: Emmer (Triticum turgidum spp. dicoccum) flour and breads. - In: Preedy V.R., Watson R.R., Patel V.B. (ed.): Flour and Breads and their Fortification in Health and Disease Prevention. Pp. 69-78. Academic Press, Elsevier, London - response to $\mathrm{N}$ fertilizer in the ancient wheats (Castagna et al. 1996, Pourazari et al. 2015). The discrepancies between our results and some of the previous reports might be due partly to the use of different plant material and mode, rate, and stage of $\mathrm{N}$ fertilization. Marino et al. (2011) indicated that $\mathrm{N}$ fertilizers applied at tillering result in improvement of grain yield but those splitted or applied at stem elongation may lead to improvement in grain protein content of rain fed emmer wheat in the Mediterranean type of climate in central Italy. On the other hand, Konvalina et al. (2012) have reported that growing emmer wheat at the presence of excess nutrients and water may lead to increase in tillering and hence lodging of this low-demanding species.

Conclusions: Water deficit adversely affected gas exchange and physiological attributes of emmer and modern wheats. However, a lesser sensitivity of $P_{\mathrm{N}}$ compared to $g_{\mathrm{s}}$ to drought resulted in an improvement in WUE $_{i}$ of examined wheats at least under the mild soil water deficit applied in our experiment. From the relative stability of $C_{\mathrm{i}}$ at the presence of varying $\mathrm{N}$ and water supplies, it may be proposed that stomatal rather than biochemical limitations account for the differences in wheat $P_{\mathrm{N}}$ and SDM between water and $\mathrm{N}$ concentrations examined. Moreover, differences in stomatal behavior, reflected in $g_{\mathrm{s}}$, seemed responsible for $P_{\mathrm{N}}$ and SDM differences in the two groups of wheat. The most interesting finding of the present study was, perhaps, that $\mathrm{N}$-supplied modern wheat plants had higher WUE $\mathrm{W}_{\mathrm{i}}$, while the reverse was true in the emmer wheats. Emmer wheat plants underwent minimal modifications in photosynthetic pigments and SDM despite contrasting water and $\mathrm{N}$ supplies. Mechanism behind this behavior is less understood and, hence, may be taken to manifest a unique characteristic of these little-known wheats which needs further study. Furthermore, in view of the prime role the Rubisco may play in plant response to varying $\mathrm{N}$ and water supplies, the future studies should focus on the quantity and specific activity of this key enzyme in the emmer wheats. In the face of ever-growing environmental concerns in relation to excessive fertilizer applications for crop production, our results imply promising perspectives to hire these rather ancient wheats in organic farming.

Burlington - San Diego 2011

Ashraf M., Arfan M., Ashraf M.Y.: Water relations, gas exchange characteristics, and the level of some metabolites in two cultivars of spring wheat under different $\mathrm{N}$ regimes. - Acta Physiol. Plant. 24: 407-415, 2002.

Askari E., Ehsanzadeh P.: Drought stress mitigation by foliar application of salicylic acid and their interactive effects on physiological characteristics of fennel (Foeniculum vulgare Mill.) genotypes. - Acta Physiol. Plant. 37: 1-14, 2015.

Araus J.L., Slafer G.A., Raynolds M.P. et al.: Plant breeding and 
drought in $\mathrm{C}_{3}$ cereals: What should we breed for? - Ann. Bot.London 89: 925-940, 2002.

Bajji M., Kinet J.M., Lutts S.: The use of the electrolyte leakage method for assessing cell membrane stability as a water stress tolerance test in durum wheat. - Plant Growth Regul. 36: 6170, 2002.

Breštič M., Živčák M., Kunderlíková K. et al.: High temperature specifically affects the photoprotective responses of chlorophyll $b$ deficient wheat mutant lines. - Photosynth. Res. 130: 251-266, 2015.

Castagna R., Minoia C., Porfiri O. et al.: Nitrogen level and seeding rate effects on the performance of hulled wheats (Triticum monococcum L., Triticum dicoccum Schübler and Triticum spelta L.) evaluated in contrasting agronomic environments. - J. Agron. Crop Sci. 176: 173-181, 1996.

Cechin I.: Photosynthesis and chlorophyll fluorescence in two hybrids of Sorghum under different nitrogen and water regimes. - Photosynthetica 35: 233-240, 1998.

Chapagain T., Riseman A.: Nitrogen and carbon transformations, water use efficiency and ecosystem productivity in monocultures and wheat-bean intercropping systems. - Nutr. Cycl. Agroecosys. 101: 107-121, 2015.

Ercoli L., Mariotti M., Masoni A. et al.: Relationship between nitrogen and chlorophyll content and spectral properties in maize leaves. - Eur. J. Agron. 2: 113-117, 1993.

Farooq M., Wahid A., Kobayashi N. et al.: Plant drought stress: effects, mechanisms and management. - Agron. Sustain. Dev. 29: 185-212, 2009.

Fischer R.A., Rees D., Sayre K.D. et al.: Wheat yield progress associated with higher stomatal conductance and photosynthetic rate, and cooler canopies. - Crop Sci. 38: 1467-1475, 1998.

Flexas J., Galmés J., Gallé A. et al.: Improving water use efficiency in grapevines: potential physiological targets for biotechnological improvement. - Aust J. Grape Wine Res. 16: 106-121, 2010.

Gadallah M.A.A.: Effect of water stress, abscisic acid and proline on cotton plants. - J. Arid Environ. 30: 315-325, 1995.

Guo W., Li B., Zhang X., Wang R.: Architectural plasticity and growth responses of Hippophae rhamnoides and Caragana intermedia seedlings to simulated water stress. - J. Arid Environ. 69: 385-399, 2007.

Kiani M., Gheysari M., Mostafazadeh-Fard B. et al.: Effect of the interaction of water and nitrogen on sunflower under drip irrigation in an arid region. - Agr. Water Manage. 171: 162172, 2016.

Konvalina P., Capouchová I., Stehno Z.: Agronomically important traits of emmer wheat. - Plant Soil Environ. 58: 341-346, 2012.

Lawlor D.W., Cornic G.: Photosynthetic carbon assimilation and associated metabolism in relation to water deficits in higher plants. - Plant Cell Environ. 25: 275-294, 2002.

Lea P.J., Azevedo R.A.: Nitrogen use efficiency. 1. Uptake of nitrogen from the soil. - Ann. Appl. Biol. 149: 243-247, 2006.

Lichtenthaler H.K., Wellburn W.R.: Determination of total carotenoids and chlorophylls $a$ and $b$ of leaf extracts in different solvents. - Biochem. Soc. T. 11: 591-592, 1994.

Liu F., Jensen C.R., Shahanzari A. et al.: ABA regulated stomatal control and photosynthetic water use efficiency of potato (Solanum tuberosum L.) during progressive soil drying. - Plant Sci. 168: 831-836, 2005.

Marino S., Cocozza C., Tognetti R., Alvino A.: Nitrogen supply effect on emmer (Triticum dicoccum Schübler) ecophysiolo-gical and yield performance. - Int. J. Plant Prod. 10: 457-468, 2016.
Marino S., Tognetti R., Alvino A.: Effects of varying nitrogen fertilization on crop yield and grain quality of emmer grown in a typical Mediterranean environment in central Italy. - Eur. J. Agron. 34: 172-180, 2011.

Medrano H., Tomás M., Martorell S. et al.: From leaf to wholeplant water use efficiency (WUE) in complex canopies: Limitations of leaf WUE as a selection target. - Crop J. 3: 220 $228,2015$.

Ögren E.: Suboptimal nitrogen status sensitizes the photosynthetic apparatus in willow leaves to long term but not short term water stress. - Photosynth. Res. 18: 263-275, 1988.

Pan X., Lada R.R., Caldwell C.D. et al.: Water-stress and Nnutrition effects on photosynthesis and growth of Brassica carinata. - Photosynthetica 49: 309-315, 2011.

Potters G., Pasternak T.P., Guisez Y. et al:: Stress-induced morphogenic responses: growing out of trouble? - Trends Plant Sci. 12: 98-105, 2007.

Pourazari F., Vico G., Ehsanzadeh P. et al.: Contrasting growth pattern and nitrogen economy in ancient and modern wheat varieties. - Can. J. Plant Sci. 95: 851-860, 2015.

Prsa I., Stampar F., Vodnik D. et al.: Influence of nitrogen on leaf chlorophyll content and photosynthesis of 'Golden Delicious' apple. - Acta Agr. Scand. B-S. P. 57: 283-289, 2007.

Robinson J.M., Burkey K.O.: Foliar $\mathrm{CO}_{2}$ photoassimilation and chloroplast linear electron transport rates in nitrogen-sufficient and nitrogen-limited soybean plants. - Photosynth. Res. 54: 209-217, 1997.

Seemann J.R., Critchley C.: Effects of salt stress on the growth, ion content, stomatal behavior and photosynthetic capacity of a salt-sensitive species, Phaseolus vulgaris L. - Planta 164: 151-162, 1985.

Shao H.B., Liang Z.S., Shao M.A.: Changes of anti-oxidative enzymes and MDA content under soil water deficits among 10 wheat (Triticum aestivum L.) genotypes at maturation stage. Colloid. Surface. B 45: 7-13, 2005.

Thormann I., Fiorino E., Halewood M. et al.: Plant genetic resources collections and associated information as a baseline resource for genetic diversity studies: an assessment of the IBPGR-supported collections. - Gen. Res. Crop Evol. 62: 1279-1293, 2015.

van Keulen H., Stol W.: Quantitative aspects of nitrogen nutrition in crops. - Fert. Res. 27: 151-160, 1991.

Venora G., Calcagno F.: Study of stomatal parameters for selection of drought resistant varieties in Triticum durum DESF. - Euphytica 57: 275-283, 1991.

Wu F.Z., Bao W.K., Zhou Z.Q. et al.: Carbon accumulation, nitrogen and phosphorus use efficiency of Sophora davidii seedlings in response to nitrogen supply and water stress. - J. Arid Environ. 73: 1067-1073, 2009.

Yousefzadeh Najafabadi M., Ehsanzadeh P.: Photosynthetic and antioxidative upregulations in drought-stressed sesame (Sesamum indicum L.) subjected to foliar-applied salicylic acid. - Photosynthetica 55: 611-622, 2017.

Zhang R.H., Zhang X.H., Camberato J.J et al.: Photosynthetic performance of maize hybrids to drought stress. - Russ. J. Plant Physl+ 62: 788-796, 2015

Zhao C., Liu Q.: Effects of soil warming and nitrogen fertilization on leaf physiology of Pinus tabulaeformis seedlings. - Acta Physiol. Plant. 34: 1837-1846, 2012.

Živčák M., Kalaji H.M., Shao H.B. et al.: Photosynthetic proton and electron transport in wheat leaves under prolonged moderate drought stress. - J. Photoch. Photobio. B 137: 2014 107-115, 2014. 